\title{
Effect of allopurinol on mortality and hospitalisations in chronic heart failure: a retrospective cohort study
}

\author{
A D Struthers, P T Donnan, P Lindsay, D McNaughton, J Broomhall, T M MacDonald
}

Heart 2002;87:229-234

See end of article for authors' affiliations

\section{Correspondence to:}

Professor Allan D Struthers,

Department of Clinical

Pharmacology \&

Therapeutics, and the

Medicines Monitoring Unit,

Ninewells Hospital,

Dundee DDI 9SY, UK:

a.d.struthers@dundee.ac.uk

Accepted

14 November 2001

\begin{abstract}
Objective: To examine whether allopurinol is associated with any alteration in mortality and hospitalisations in patients with chronic heart failure (CHF). This hypothesis is based on previous data that a high urate concentration is independently associated with mortality with a risk ratio of 4.23 in CHF.

Design: Retrospective cohort study.

Setting: Medicines Monitoring Unit, Ninewells Hospital, Dundee, UK.

Patients: $1760 \mathrm{CHF}$ patients divided into four groups: those on no allopurinol, those on long term low dose allopurinol, those on short term low dose allopurinol, and those on long term high dose allopurinol.

Main outcome measures: Total mortality, cardiovascular mortality, cardiovascular hospitalisations, cardiovascular mortality or hospitalisations.

Results: Long term low dose allopurinol was associated with a significant worsening in mortality over those who never received allopurinol (relative risk 2.04, 95\% confidence interval (CI) 1.48 to 2.81). This may be because low dose allopurinol is insufficient to negate the adverse effect of a high urate concentration. However, long term high dose ( $\geqslant 300 \mathrm{mg} /$ day) allopurinol was associated with a significantly better mortality than longstanding low dose allopurinol (relative risk $0.59,95 \% \mathrm{Cl} 0.37$ to 0.95). This may mean that high dose allopurinol can fully negate the adverse effect of urate and return the mortality to normal.

Conclusions: Long term high dose allopurinol may be associated with a better mortality than long term low dose allopurinol in patients with CHF because of a dose related beneficial effect of allopurinol against the well described adverse effect of urate. Further work is required to substantiate or refute this finding.
\end{abstract}

$\mathrm{T}$ here are increasing data suggesting that uric acid may be a major culprit in cardiovascular disease. In fact, three types of data attest that uric acid per se is harmful. Firstly, exogenous uric acid causes endothelial dysfunction when infused into the human brachial artery. ${ }^{1}$ Secondly, endogenous uric acid concentrations correlate with endothelial dysfunction. $^{2}$ Thirdly, in numerous population studies uric acid has been shown to be an independent predictor of mortality, including one large study in patients with chronic heart failure (CHF). . $^{-8}$

These data obviously raise the possibility that reducing uric acid with allopurinol might also reduce cardiovascular events. This prospect is made even more likely because as well as reducing uric acid, which might be beneficial, allopurinol has a second and completely different action that might also reduce cardiovascular events. That second effect of allopurinol is to reduce superoxide anion production because xanthine oxidase is one of the main producers of superoxide anions..$^{9-11}$ The importance of this second effect of allopurinol is that superoxide anions are well known to inactivate endogenous nitric oxide and therefore allopurinol should boost endogenous vascular nitric oxide bioactivity. ${ }^{12}{ }^{13}$

If the above theoretical benefits of allopurinol actually were to occur in practice, then one would expect that xanthine oxidase inhibition would be able to improve endothelial dysfunction in humans. In fact, three studies now clearly show this to be the case. ${ }^{14-16}$

The prospect therefore arises that allopurinol might reduce cardiovascular events in at risk patients. Indeed, whether this is the case or not has become a key question in cardiovascular medicine. A full randomised placebo controlled trial would be the ideal way to answer this question. However, before any funding agency is likely to use their limited resources to fund such an expensive trial, more confirmatory data are required, especially data linking allopurinol directly to cardiovascular events rather than merely linking allopurinol with promising surrogates, which is all that we currently have. To perform such a study, the Medicines Monitoring Unit (MEMO) at Ninewells Hospital was used to identify retrospectively a cohort of patients with CHF in 1993. We then examined whether those CHF patients who received allopurinol had fewer cardiovascular events than those who did not receive allopurinol.

Clearly any comparison of the two groups had to take carefully into account the diuretic dose as this not only indicated the severity of the underlying CHF disease but also was the driving force for gout to appear. Another complicating factor that needed to be taken into account is that, at the same diuretic dose, those with a high urate concentration are known to have a much worse prognosis. Indeed, in the only study of patients with CHF, the relative risk of an above median urate concentration was as high as 4.23 and that risk was independent of diuretic dose. ${ }^{3}$

\section{METHODS}

This study was carried out using the record linkage system of the MEMO at Ninewells Hospital, Dundee, UK. The workings of this database and its methods of collection have been

Abbreviations: $A C E$, angiotensin converting enzyme; $C H F$, chronic heart failure; ICD-9, International classification of diseases, ninth revision; MEMO, Medicines Monitoring Unit; RCT, randomised controlled trial; SAVE, survival and ventricular enlargement 
Table 1 Characteristics of the chronic heart failure cohort $(n=1760)$ on 1 July 1993 by previous and current allopurinol (A) exposure

\begin{tabular}{|c|c|c|c|c|c|}
\hline & Never & $\begin{array}{l}\text { Recent low } \\
\text { dose A }\end{array}$ & $\begin{array}{l}\text { Long standing } \\
\text { low dose A }\end{array}$ & $\begin{array}{l}\text { Long standing } \\
\text { high dose A }\end{array}$ & p Value \\
\hline Number & 1593 & 72 & 48 & 47 & \\
\hline Mean (SD) age (years) & $68.0(10.7)$ & $66.1(9.7)$ & $65.4(10.0)$ & $65.7(9.2)$ & 0.712 \\
\hline Mean (SD) time from first MI to 1993 (years) & $5.14(3.81)$ & $5.72(3.67)$ & $5.64(3.77)$ & $6.71(3.17)$ & 0.02 \\
\hline Mean (SD) number of Mls before 1993 & $2.06(1.03)$ & $2.47(1.07)$ & $2.02(1.02)$ & $2.40(1.17)$ & 0.0015 \\
\hline Men & $784(49.2 \%)$ & $45(62.5 \%)$ & $27(56.3 \%)$ & $37(78.7 \%)$ & 0.001 \\
\hline Women & $809(50.8 \%)$ & $27(37.5 \%)$ & $21(43.7 \%)$ & $10(21.3 \%)$ & \\
\hline \multicolumn{6}{|l|}{ Social deprivation } \\
\hline 1 & $99(6.2 \%)$ & $5(6.9 \%)$ & $5(10.4 \%)$ & $2(4.3 \%)$ & 0.54 \\
\hline 2 & $223(14.1 \%)$ & $17(23.6 \%)$ & $8(16.7 \%)$ & $5(10.6 \%)$ & \\
\hline 3 & $373(23.5 \%)$ & $14(19.4 \%)$ & $10(20.8 \%)$ & $15(31.9 \%)$ & \\
\hline 4 & $337(21.2 \%)$ & $14(19.4 \%)$ & $13(27.1 \%)$ & $12(25.5 \%)$ & \\
\hline 5 & $194(12.2 \%)$ & $5(6.9 \%)$ & $5(10.4 \%)$ & $5(10.6 \%)$ & \\
\hline $6 / 7$ & $361(22.8 \%)$ & $17(23.6 \%)$ & $7(14.6 \%)$ & $8(17.0 \%)$ & \\
\hline Diabetes & $102(6.4 \%)$ & $5(6.9 \%)$ & $0(0.0 \%)$ & $2(4.3 \%)$ & 0.08 \\
\hline \multicolumn{6}{|l|}{ Loop diuretic dose } \\
\hline Low & 1099 (69.0\%) & $36(50.0 \%)$ & $19(39.6 \%)$ & $22(46.8 \%)$ & 0.001 \\
\hline Medium & $426(26.7 \%)$ & $26(36.1 \%)$ & $21(43.8 \%)$ & $21(44.7 \%)$ & \\
\hline High & $68(4.3 \%)$ & $10(13.9 \%)$ & $8(16.7 \%)$ & $4(8.5 \%)$ & \\
\hline \multicolumn{6}{|l|}{ History } \\
\hline Use of NSAIDs & $85(5.3 \%)$ & $3(4.2 \%)$ & $5(10.4 \%)$ & $7(14.9 \%)$ & 0.018 \\
\hline Use of thiazides & $76(4.8 \%)$ & $8(11.1 \%)$ & $2(4.2 \%)$ & $3(6.4 \%)$ & 0.11 \\
\hline Respiratory illness & $481(30.2 \%)$ & $29(40.3 \%)$ & $20(41.7 \%)$ & $14(29.8 \%)$ & 0.11 \\
\hline Renal disease & $175(11.0 \%)$ & $6(8.3 \%)$ & $5(10.4 \%)$ & $5(10.6 \%)$ & 0.92 \\
\hline Hypertension & $95(6.0 \%)$ & $6(8.3 \%)$ & $5(10.4 \%)$ & $5(10.6 \%)$ & 0.30 \\
\hline \multicolumn{6}{|l|}{ Drugs in concurrent use } \\
\hline Aspirin & $893(56.1 \%)$ & $46(63.9 \%)$ & 25 (52.1\%) & $24(51.1 \%)$ & 0.46 \\
\hline Anticoagulants & $137(8.6 \%)$ & $15(20.8 \%)$ & $6(12.5 \%)$ & $7(14.9 \%)$ & 0.002 \\
\hline ACE inhibitors & $573(36.0 \%)$ & $39(54.2 \%)$ & $22(45.8 \%)$ & $20(42.6 \%)$ & 0.007 \\
\hline$\beta$ Blockers & $298(18.75 \%)$ & $39(54.2 \%)$ & $6(12.5 \%)$ & $11(23.4 \%)$ & 0.49 \\
\hline Nitrates & $1092(68.6 \%)$ & $54(75.0 \%)$ & 31 (64.6\%) & $36(76.6 \%)$ & 0.38 \\
\hline Digoxin & $357(22.45 \%)$ & $31(43.1 \%)$ & $13(27.1 \%)$ & $12(25.5 \%)$ & 0.001 \\
\hline $\mathrm{K}^{+}$sparing diuretics & $980(61.5 \%)$ & $39(54.2 \%)$ & $23(47.9 \%)$ & $31(66.0 \%)$ & 0.14 \\
\hline Antiarrhythmics & $65(4.1 \%)$ & $7(9.7 \%)$ & $1(2.1 \%)$ & $1(2.1 \%)$ & 0.09 \\
\hline
\end{tabular}

described in detail elsewhere. ${ }^{17}$ Basically, MEMO has information on all drugs dispensed, hospitalisations from Scottish Morbidity Records, and deaths and their causes in the population of Tayside in Scotland.

\section{Entry criteria}

The MEMO database was firstly used to identify a cohort of patients who have CHF. To identify them, we could have simply used all patients on loop diuretics but the latter are prescribed in some non-CHF situations (for example, renal hypertension or to elderly women with swollen ankles caused by venous disease) so that we felt it better to identify a more specific cohort of CHF patients. We did this by firstly identifying a fixed cohort of patients who satisfied the following criteria: they had at least one admission for myocardial infarction between 1980 and July 1993; and they were receiving loop diuretic medication between l January and June 1993 (thiazide diuretics were not an entry criteria as this might capture patients who are hypertensive with small myocardial infarctions). Patients were excluded if their plasma creatinine concentration was $>200 \mathrm{~m} / \mathrm{mol}$ on 1 July 1993. Since most hypertensive patients who receive loop diuretics have renal disease, this helped to exclude renal hypertension without CHF.

We have successfully used the above entry criteria in previous MEMO studies to identify a cohort of CHF patients. ${ }^{18}$ In all studies so far, a previous myocardial infarction was the main risk factor for developing heart failure, which is why we used this criterion. Loop diuretics are universally given to patients with symptomatic, suspected heart failure. Although not perfect, the combination of these two criteria has previously been accepted as the best possible way of identifying CHF from large datasets such as MEMO. ${ }^{18}$ Case note validation (see below) was undertaken in a sample to verify the accuracy of the diagnosis of CHF. It is accepted that this technique misses patients with dilated cardiomyopathies, but such patients are in the minority in Scotland.

\section{Study period}

Patients with CHF were all identified at I July 1993 and followed up to March 1999 for mortality, although only to March 1997 for hospitalisation, giving a minimum follow up of around four years (1993-1997). Patients were censored at death or at the end of the study period, whichever was the earlier.

\section{Allopurinol cohort}

From the study cohort, patients who were receiving allopurinol medication on entry to the study were identified and formed the allopurinol cohort.

\section{Non-allopurinol cohort}

The non-allopurinol cohort was made up of comparators who fulfilled the entry criteria and who were not receiving allopurinol on entry to the study.

\section{Outcomes}

As far as outcomes are concerned, it is worth noting that MEMO should have $100 \%$ complete follow up data for deaths anywhere in the world and 100\% complete follow up for hospitalisations within Tayside. ${ }^{17}$

The main end points were the following:

- all cause mortality

- cardiovascular mortality (International classification of diseases, ninth revision (ICD-9) primary codes of death 390-459) 


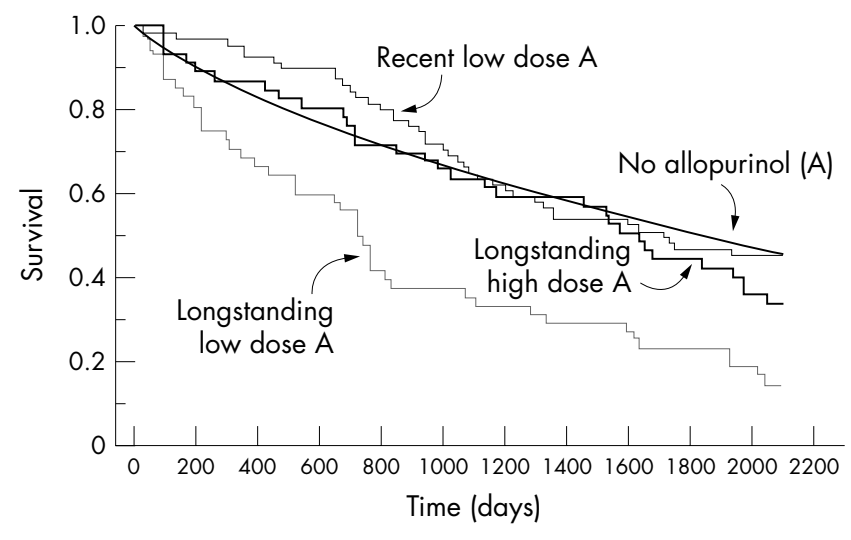

Figure 1 All cause mortality by whether patients did or did not receive allopurinol. The treatment groups are (1) no allopurinol, (2) recent low dose allopurinol, (3) longstanding low dose allopurinol, and (4) longstanding high dose allopurinol.

- time to first emergency cardiovascular hospitalisation (defined as the primary reason for admission being coded in ICD-9 as 410, 411, 413, 414.0, 414.1, 414.8, 414.9, 425, 427, 428.0, 428.1, 429.1, 429.2, 429.3, 429.4, 429.5, 429.6, 429.8 or 429.9 )

- all cause mortality or time to first emergency cardiovascular hospitalisation (as defined above).

\section{Statistical methods}

Time to death and time to hospitalisation in those receiving and those not receiving allopurinol were compared using the Cox's proportional hazards model.

In addition, we were able from the MEMO prescription database to assess actual exposure and dose of allopurinol in the allopurinol cohort. This allowed us to examine whether there was any evidence of a dose related effect of allopurinol. If found, this would be consistent with a causal effect.

The proportional hazards regression was adjusted for a number of potential confounders. The following variables were assessed: age, sex, Carstairs deprivation score, ${ }^{19}$ loop diuretic dose on entry (low $\leqslant 40 \mathrm{mg}$; medium 4l-119 mg; high $\geqslant 120 \mathrm{mg}$ ), allopurinol dose (low < $299 \mathrm{mg}$; high $\geqslant 300 \mathrm{mg}$ ), and concurrent use of aspirin, other anticoagulants, angiotensin converting enzyme (ACE) inhibitor, $\beta$ blocker, digoxin, antiarrhythmics, $\mathrm{K}^{+}$sparing diuretics, or nitrates at any time during the study period. In addition, prior use of non-steroidal anti-inflammatory drugs or thiazides, and prior respiratory illness, renal disease, and hypertension were also considered to be covariates. Correcting for confounding variables is obviously crucial. This was done by entering all confounding variables individually as above into the proportional hazards model to see initially which ones were significant for the various end points. Finally, all variables were entered simultaneously to assess the independence of any significant associations found.

It is important in studies such as this to double check random samples of the case notes to ensure that the allocation of treatments (allopurinol or not) was correct and that the patients truly had CHF. We did this in all those who received allopurinol as well as in a random 5\% sample of the non-allopurinol cohort. In all cases, one nurse validated the case records. MEMO carries out all record linkage studies anonymously using encrypted data but the case record validation required decrypting of some of the person specific data. Permission was obtained from the Tayside committee on research medical ethics and from the Caldicott Guardians for both the Tayside University Healthcare Trust and the Primary Care Trusts for this case record validation to be undertaken.

\section{RESULTS}

Table 1 describes the demography of the CHF cohort $(n=1760)$ identified. To explain the data fully, the cohort was

Table 2 Results of the proportional hazards model for all cause mortality and cardiovascular mortality $(n=1760)$ in relation to allopurinol exposure, showing relative hazard with $95 \%$ confidence intervals in brackets

\begin{tabular}{|c|c|c|c|c|}
\hline & \multicolumn{2}{|l|}{ All cause mortality $(n=971)$} & \multicolumn{2}{|c|}{ Cardiovascular mortality $(n=588)$} \\
\hline & Unadjusted & Adjusted & Unadjusted & Adjusted \\
\hline \multicolumn{5}{|l|}{ Allopurinol exposure } \\
\hline Recent low dose $v$ never & $0.96(0.70$ to 1.33$)$ & $0.90(0.65$ to 1.25$)$ & $1.09(0.73$ to 1.61$)$ & $0.97(0.65$ to 1.46$)$ \\
\hline Longstanding low dose $v$ never & $2.37(1.73 \text { to } 3.24)^{* * * *}$ & $2.04(1.43 \text { to } 2.81)^{* *}$ & $2.82(1.94 \text { to } 4.10)^{* * * *}$ & $2.40(1.63 \text { to } 3.52)^{* * * *}$ \\
\hline Longstanding high dose $v$ never & $1.25(0.87$ to 1.79$)$ & $1.20(0.83$ to 1.74$)$ & $1.77(1.20 \text { to } 2.63)^{* * *}$ & $1.68(1.12 \text { to } 2.53)^{* *}$ \\
\hline $\begin{array}{l}\text { Longstanding high dose } v \text { longstanding } \\
\text { low dose }\end{array}$ & $0.53(0.33 \text { to } 0.84)^{* * *}$ & $0.59(0.37 \text { to } 0.95)^{* *}$ & $0.63(0.37 \text { to } 1.07)^{*}$ & $0.70(0.41$ to 1.20$)$ \\
\hline \multicolumn{5}{|l|}{ Loop diuretic dose } \\
\hline Medium $v$ low & $1.54(1.34 \text { to } 1.76)^{* * * *}$ & $1.42(1.29 \text { to } 1.72)^{* * * *}$ & $1.50(1.26 \text { to } 1.79)^{* * * *}$ & $1.43(1.19 \text { to } 1.72)^{* * * *}$ \\
\hline High $v$ low & $1.91(1.47 \text { to } 2.48)^{* * * *}$ & $2.05(1.55 \text { to } 2.71)^{* * * *}$ & $2.03(1.47 \text { to } 2.81)^{* * * *}$ & $2.02(1.42 \text { to } 2.87)^{* * * *}$ \\
\hline Age (+ 10 years) & $1.50(1.41 \text { to } 1.60)^{* * * *}$ & $2.07(1.91 \text { to } 2.25)^{* * * *}$ & $1.35(1.25 \text { to } 1.46)^{* * * *}$ & $1.32(1.20 \text { to } 1.44)^{* * * *}$ \\
\hline Men $v$ women & $1.16(1.03 \text { to } 1.32)^{* *}$ & $1.46(1.36 \text { to } 1.57)^{* \star * *}$ & $1.08(0.92$ to 1.27$)$ & $1.19(1.00 \text { to } 1.41)^{*}$ \\
\hline Social deprivation (+ 1 category) & $0.97(0.93 \text { to } 1.01)^{*}$ & $1.04(1.00 \text { to } 1.09)^{*}$ & $0.99(0.93$ to 1.04$)$ & $1.05(0.99 \text { to } 1.11)^{*}$ \\
\hline Number of prior Mls (+ 1) & $0.98(0.92$ to 1.04$)$ & $1.10(1.03 \text { to } 1.18)^{* * *}$ & $1.02(0.94$ to 1.10$)$ & $1.10(1.01 \text { to } 1.20)^{* *}$ \\
\hline Diabetes & $0.25(0.18 \text { to } 0.37)^{* * * *}$ & $0.28(0.20 \text { to } 0.41)^{* * * *}$ & $0.26(0.16 \text { to } 0.42)^{* * * *}$ & $0.27(0.17 \text { to } 0.44)^{* * * *}$ \\
\hline \multicolumn{5}{|c|}{ 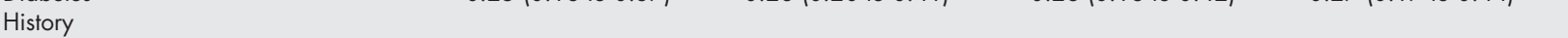 } \\
\hline Use of NSAIDs & $1.36(1.05 \text { to } 1.76)^{* *}$ & $1.29(0.99 \text { to } 1.68)^{*}$ & $1.50(1.09 \text { to } 2.06)^{* *}$ & $1.37(0.99 \text { to } 1.89)^{*}$ \\
\hline Use of thiazides & $1.23(0.94$ to 1.61$)$ & $1.15(0.88$ to 1.51$)$ & $1.10(0.76$ to 1.58$)$ & $1.03(0.72$ to 1.49$)$ \\
\hline Respiratory illness & $1.57(1.38 \text { to } 1.79)^{* * * *}$ & $1.32(1.16 \text { to } 1.52)^{* * * *}$ & $1.33(1.12 \text { to } 1.58)^{* * *}$ & $1.13(0.94$ to 1.35$)$ \\
\hline Renal disease & $1.16(0.95$ to 1.41$)$ & $0.94(0.77$ to 1.14$)$ & $1.22(0.95$ to 1.56$)$ & $1.04(0.81$ to 1.33$)$ \\
\hline Hypertension & $1.10(0.85$ to 1.42$)$ & $1.16(0.89$ to 1.52$)$ & $1.23(0.90$ to 1.68$)$ & 1.19 (0.86 to 1.64$)$ \\
\hline \multicolumn{5}{|l|}{ Drugs in concurrent use } \\
\hline Aspirin & $0.64(0.56 \text { to } 0.72)^{* * * *}$ & $0.69(0.60 \text { to } 0.79)^{* * * *}$ & $0.68(0.58 \text { to } 0.80)^{* * * *}$ & $0.73(0.62 \text { to } 0.86)^{* * * *}$ \\
\hline Anticoagulants & $0.70(0.55 \text { to } 0.89)^{* * *}$ & $0.67(0.52 \text { to } 0.86)^{* * *}$ & $0.76(0.56 \text { to } 1.01)^{*}$ & $0.66(0.49 \text { to } 0.90)^{* * *}$ \\
\hline ACE inhibitors & $0.85(0.75 \text { to } 0.97)^{* *}$ & $0.84(0.73 \text { to } 0.98)^{* *}$ & $1.03(0.87$ to 1.22$)$ & $0.97(0.80$ to 1.17$)$ \\
\hline$\beta$ Blockers & $0.41(0.34 \text { to } 0.51)^{* * * *}$ & $0.55(0.45 \text { to } 0.69)^{* * * *}$ & $0.49(0.38 \text { to } 0.62)^{* * * *}$ & $0.61(0.48 \text { to } 0.79)^{* * * *}$ \\
\hline Nitrates & $0.74(0.65 \text { to } 0.84)^{* * * *}$ & $0.84(0.74 \text { to } 0.97)^{* *}$ & $0.79(0.67 \text { to } 0.94)^{* * *}$ & $0.86(0.72 \text { to } 1.03)^{*}$ \\
\hline Digoxin & $1.36(1.19 \text { to } 1.57)^{* * * *}$ & 1.09 (0.94 to 1.27$)$ & $1.51(1.27 \text { to } 1.80)^{* * * *}$ & $1.24(1.03 \text { to } 1.50)^{* *}$ \\
\hline $\mathrm{K}^{+}$sparing diuretics & $1.03(0.90$ to 1.17$)$ & $0.83(0.72 \text { to } 0.95)^{* * *}$ & $0.94(0.80$ to 1.11$)$ & $0.83(0.69 \text { to } 0.99)^{* *}$ \\
\hline Antiarrhythmics & 0.79 (0.57 to 1.09$)$ & $0.74(0.53 \text { to } 1.03)^{*}$ & $0.95(0.65$ to 1.40$)$ & $0.88(0.60$ to 1.31$)$ \\
\hline
\end{tabular}


Table 3 Results of the proportional hazards model for cardiovascular hospitalisation and mortality and cardiovascular hospitalisation $(n=1760)$ in relation to allopurinol exposure, showing relative hazard with $95 \%$ confidence intervals in brackets

\begin{tabular}{|c|c|c|c|c|}
\hline & \multicolumn{2}{|l|}{ CV hospitalisation $(n=566)$} & \multicolumn{2}{|c|}{ Mortality or cardiovascular hospitalisation $(n=1002)$} \\
\hline & Unadjusted & Adjusted & Unadjusted & Adjusted \\
\hline \multicolumn{5}{|l|}{ Allopurinol exposure } \\
\hline Recent low dose $v$ never & $1.64(1.16 \text { to } 2.32)^{* * *}$ & $1.23(0.86$ to 1.76$)$ & $1.41(1.06 \text { to } 1.86)^{* *}$ & $1.14(0.86$ to 1.53$)$ \\
\hline Longstanding low dose $v$ never & $2.64(1.79 \text { to } 3.90)^{* * * *}$ & $2.31(1.55 \text { to } 3.46)^{* * * *}$ & $2.15(1.56 \text { to } 2.96)^{* * * *}$ & $1.71(1.23 \text { to } 2.38)^{* * *}$ \\
\hline Longstanding high dose $v$ never & $1.20(0.74$ to 1.94$)$ & $1.13(0.69$ to 1.86$)$ & $1.05(0.72$ to 1.54$)$ & $0.96(0.64$ to 1.42$)$ \\
\hline $\begin{array}{l}\text { Longstanding high dose } v \text { longstanding } \\
\text { low dose }\end{array}$ & $0.45(0.25 \text { to } 0.83)^{* *}$ & $0.49(0.26$ to 0.91$)$ ** & $0.49(0.30 \text { to } 0.80)^{* * *}$ & $0.56(0.34 \text { to } 0.92)^{* *}$ \\
\hline \multicolumn{5}{|l|}{ Loop diuretic dose } \\
\hline Medium $v$ low & $1.58(1.32 \text { to } 1.89)^{* * * *}$ & $1.32(1.10 \text { to } 1.59)^{* * *}$ & $1.56(1.37$ to 1.79$) * * * *$ & $1.41(1.23 \text { to } 1.62)^{* * * *}$ \\
\hline High $v$ low & $3.09(2.29$ to 4.16$) * * * *$ & $1.78(1.28 \text { to } 2.47)^{* * * *}$ & $2.58(2.02 \text { to } 3.28)^{* * * *}$ & $2.04(1.57$ to 2.66$) * * * *$ \\
\hline Age (+ 10 years) & $1.04(0.96$ to 1.12$)$ & $1.20(1.09 \text { to } 1.31)^{* * * *}$ & $1.20(1.13 \text { to } 1.28)^{* * * *}$ & $1.27(1.19 \text { to } 1.36)^{* * * *}$ \\
\hline Men $v$ women & $1.02(0.87$ to 1.21$)$ & $0.93(0.78$ to 1.11$)$ & $1.12(0.99 \text { to } 1.26)^{*}$ & $1.14(1.00 \text { to } 1.30)^{* *}$ \\
\hline Social deprivation (+ 1 category) & $1.13(1.07 \text { to } 1.19)^{* * * *}$ & $1.12(1.06 \text { to } 1.18)^{* * * *}$ & $1.05(1.01 \text { to } 1.09)^{* *}$ & $1.07(1.03 \text { to } 1.12)^{* * * *}$ \\
\hline Number of prior Mls (+ 1) & $1.22(1.13 \text { to } 1.32)^{* \star * *}$ & $1.13(1.04 \text { to } 1.22)^{* * *}$ & $1.09(1.03 \text { to } 1.16)^{* * *}$ & $1.11(1.04 \text { to } 1.18)^{* \star *}$ \\
\hline Diabetes & $0.90(0.67$ to 1.22$)$ & $0.79(0.58$ to 1.07$)$ & $0.48(0.36 \text { to } 0.65)^{* * * *}$ & $0.48(0.35 \text { to } 0.65)^{* * * *}$ \\
\hline \multicolumn{5}{|c|}{$x_{1}$} \\
\hline Use of NSAIDs & $1.17(0.81$ to 1.68$)$ & $1.02(0.70$ to 1.48$)$ & $1.51(1.18 \text { to } 1.93)^{* * * *}$ & $1.34(1.04 \text { to } 1.72)^{* *}$ \\
\hline Use of thiazides & $1.14(0.79$ to 1.63$)$ & $1.00(0.69$ to 1.45$)$ & $1.14(0.87$ to 1.50$)$ & 1.04 (0.79 to 1.37 ) \\
\hline Respiratory illness & $1.26(1.06 \text { to } 1.51)^{* * *}$ & 1.07 (0.89 to 1.29$)$ & $1.46(1.29 \text { to } 1.66)^{* * * *}$ & $1.24(1.08 \text { to } 1.42)^{* * *}$ \\
\hline Renal disease & $0.70(0.51$ to 0.95$)$ & $0.67(0.49$ to 0.91$)$ ** & $1.01(0.82$ to 1.23$)$ & $0.90(0.74$ to 1.10$)$ \\
\hline Hypertension & $1.23(0.89$ to 1.70$)$ & $1.08(0.78$ to 1.51$)$ & $1.26(0.99 \text { to } 1.61)^{*}$ & $1.20(0.94$ to 1.55$)$ \\
\hline \multicolumn{5}{|l|}{ Drugs in concurrent use } \\
\hline Aspirin & $1.11(0.94$ to 1.31$)$ & $1.05(0.88$ to 1.25$)$ & $0.83(0.74 \text { to } 0.94)^{* * *}$ & $0.84(0.74 \text { to } 0.96)^{* *}$ \\
\hline Anticoagulants & $1.69(1.34 \text { to } 2.14)^{* * * *}$ & $1.30(1.01 \text { to } 1.68)^{* *}$ & 1.22 (1.00 to 1.49$)$ & 1.05 (0.85 to 1.29 ) \\
\hline ACE inhibitors & $1.92(1.63 \text { to } 2.26)^{* * * *}$ & $1.71(1.41 \text { to } 2.07)^{* * * *}$ & $1.30(1.15 \text { to } 1.48)^{* * * *}$ & $1.19(1.03 \text { to } 1.38)^{* *}$ \\
\hline$\beta$ Blockers & $0.94(0.76$ to 1.16$)$ & 1.09 (0.87 to 1.36$)$ & $0.69(0.58 \text { to } 0.82)^{* * * *}$ & $0.87(0.73$ to 1.05$)$ \\
\hline Nitrates & $1.87(1.52 \text { to } 2.30)^{* * * *}$ & $1.65(1.33 \text { to } 2.04)^{* * * *}$ & 1.09 (0.95 to 1.25$)$ & 1.09 (0.94 to 1.25$)$ \\
\hline Digoxin & $1.59(1.33 \text { to } 1.90)^{* * * *}$ & $1.25(1.03 \text { to } 1.52)^{* *}$ & $1.44(1.26 \text { to } 1.66)^{* * * *}$ & $1.13(0.98$ to 1.31$)$ \\
\hline $\mathrm{K}^{+}$sparing diuretics & $1.02(0.86$ to 1.21$)$ & $1.18(0.98 \text { to } 1.42)^{*}$ & $0.97(0.85$ to 1.10$)$ & 0.95 (0.83 to 1.09$)$ \\
\hline Antiarrhythmics & $1.85(1.34 \text { to } 2.54)^{* * * *}$ & $1.46(1.05 \text { to } 2.03)^{* *}$ & $1.20(0.90$ to 1.61$)$ & 1.03 (0.77 to 1.39$)$ \\
\hline
\end{tabular}

divided into four groups: (1) those who had never received allopurinol; (2) those who received no allopurinol before 1 July 1993 but were on low dose allopurinol during the study period (1993-1997) (hereafter also called the recent low dose allopurinol group); (3) those who received allopurinol before 1 July 1993 and were on low dose allopurinol during the study period (1993-1997) (hereafter also called the longstanding low dose allopurinol group); (4) those who received allopurinol before 1 July 1993 and were on high dose allopurinol during the study period (hereafter also called the longstanding high dose allopurinol group).

The importance of using allopurinol before 1 July 1993 as a factor is that it contains important information on the duration for which the patient was exposed to a putative beneficial treatment (allopurinol). Most treatments exhibit a duration-effect relation in terms of their ability to alter major clinical events.

The four groups differed (as expected) in certain parameters (table 1).

It is worth noting that all those on high dose allopurinol were also on allopurinol before 1993, which means that the fairest comparison for them is with those on low dose allopurinol who also used allopurinol before 1993. This is fairest because both groups were exposed to allopurinol's therapeutic effect for the same duration. Table 1 shows the demographic breakdown of the four groups. The data in table l suggest that although there were some demographic differences between the groups the differences were not all in the same direction and might well be expected in general to balance each other out. Importantly, these differences were taken into account by adjusting for these covariates in the proportional hazards regression. In the case record validation subset, $95 \%$ of patients labelled as having CHF did indeed have CHF and the allocation to receiving allopurinol or not was $100 \%$ accurate.
Figure 1 shows the Kaplan-Meier survival curves for the four allopurinol exposure groups. The curves show that total mortality was similar in all groups, except that the longstanding low dose allopurinol group had a worse mortality than the other three groups. This could be because the latter group was exposed to an inadequately treated urate concentration for a longer time. An alternative explanation is that low dose allopurinol is positively harmful when taken over a long period of time but this seems less likely since there are no known adverse effects of allopurinol and because high dose allopurinol was, if anything, beneficial.

Tables 2 and 3 show the proportional hazards regression analysis in greater detail. The important finding is that longstanding low dose allopurinol was associated with increased mortality while longstanding high dose allopurinol was associated with the same mortality as the no allopurinol group. This means that longstanding high dose allopurinol was significantly better than longstanding low dose allopurinol. The data on cardiovascular mortality, cardiovascular hospitalisations, and their combination are essentially the same as the mortality data for allopurinol (table 4). Tables 2 and 3 also show the expected beneficial effect of ACE inhibitors, $\beta$ blockers, and aspirin on mortality in this cohort, which adds some validity to our dataset and our analyses. Data in these tables also suggest that anticoagulants and aspirin may be particularly beneficial on mortality, which corroborates similar analysis of the SAVE (survival and ventricular enlargement) study population..$^{20}$ For these non-allopurinol drugs, the hospitalisation data are sometimes dissimilar to the mortality data, which could be because of drug side effects causing admissions such as bleeding with aspirin and anticoagulants or hypotension and renal dysfunction with ACE inhibitors. The only major surprise in all these data is the apparently beneficial effect of diabetes, for which we have no explanation. 
Table 4 Crude number of events in each of the allopurinol subgroups

\begin{tabular}{lllll}
\hline & $\begin{array}{l}\text { No } \\
\text { allopurinol } \\
(\mathbf{n}=1593)\end{array}$ & $\begin{array}{l}\text { Recent low dose } \\
\text { allopurinol } \\
(\mathbf{n}=72)\end{array}$ & $\begin{array}{l}\text { Long standing low } \\
\text { dose allopurinol } \\
(\mathbf{n}=48)\end{array}$ & $\begin{array}{l}\text { Long standing high } \\
\text { dose allopurinol } \\
(\mathrm{n}=47)\end{array}$ \\
\hline Mortality & 860 & 39 & 41 & 31 \\
CV mortality & 507 & 26 & 29 & 26 \\
CV hospitalisations & 488 & 34 & 27 & 17 \\
CV mortality or hospitalisations & 884 & 52 & 39 & 27
\end{tabular}

These data do not take into account the time to each event, which is taken into account in all other analyses.

$\mathrm{CV}$, cardiovascular.

\section{DISCUSSION}

Our retrospective cohort study is certainly not as definitive as a fully randomised controlled trial (RCT) but there are some well recognised advantages of this kind of study over an RCT. For example, the average age in many RCTs involving patients with CHF is often 62 years, whereas the average age of these patients in the real world is usually higher, the average age in this study being 68 years. The other criticism of many RCTs in CHF is that comorbidity often excludes a patient from taking part in an RCT, whereas comorbid conditions are extremely common in real life elderly CHF patients. Thus, an advantage of our retrospective study is that neither age nor comorbidity nor indeed any factor at all led to a patient being excluded, which means that the population that we studied was representative of patients with routine ischaemic CHF in the UK.

It may be argued that all we have found here is that the longstanding low dose allopurinol group happened by chance to have a significantly worse mortality than all other groups and that overall allopurinol probably has no effect. Although this is certainly possible, the previous work relating high urate concentration to mortality (relative risk 4.23) makes it unlikely that our low dose results happened by chance. It would be quite a coincidence if longstanding low dose allopurinol use had increased mortality by chance in this study while longstanding high urate concentrations (which were very likely to have been present in our low dose allopurinol group) are already known to be linked to increased mortality from other studies. Therefore, it seems quite possible that the high risk associated with a longstanding high urate concentration is inadequately reduced by longstanding low dose allopurinol. That is why longstanding low dose allopurinol is associated with increased risk.

Our finding that longstanding high dose allopurinol was associated with a significantly lower mortality than longstanding low dose allopurinol should also be assessed along with the previous observation by Anker and colleagues ${ }^{3}$ that a high uric acid concentration identifies a group at particularly high risk (relative risk 4.23), irrespective of diuretic dose. Therefore, a possible conclusion from this study is that the ability of longstanding gout and a high uric acid concentration to identify a high risk group is little altered by long term low dose allopurinol. However, long term high dose allopurinol may be able to reverse that risk and return these patients to the risk normally found in patients with CHF who do not have gout. In fact, the relative risk of an above median urate concentration of $4.23^{3}$ means that it was never likely that, in this study, allopurinol would be associated with a better overall mortality than no allopurinol because, to do this, allopurinol would need to totally negate a relative risk of 4.23 plus provide an added benefit. No drug that improves mortality has ever had such a dramatic effect. This is why our finding that high dose allopurinol was associated with the same mortality as no allopurinol should not be dismissed since this is the most that allopurinol was ever likely to achieve in this kind of study.

Clearly, the allopurinol subgroups in this study were relatively small, which means that this study was more of a hypothesis generating pilot study rather than providing a definitive result. However, the difference we saw between high and low dose allopurinol does fulfill some of the criteria that epidemiologists look for to assess causation in observational studies. ${ }^{21}$ Firstly, the finding of a dose-response trend with any drug is generally seen to lend important support to the idea that the drug is exerting a true biological effect rather than that the findings are due to chance. This is especially true in the present study, where the low dose used ( $100 \mathrm{mg} /$ day) is only $10 \%$ of the maximum recommended dose of allopurinol $(<1 \mathrm{~g} /$ day $)$. Indeed, it would surprising if such a small dose of allopurinol ( $100 \mathrm{mg} /$ day) were to have any effect on such a major complex event as death, especially since it is working against such a high relative risk for urate. Furthermore, it is worth noting that the two studies that showed that allopurinol improved endothelial dysfunction both used the higher, $300 \mathrm{mg}$ /day dose of allopurinol, which also produced apparent benefit here. ${ }^{15}{ }^{16}$ Secondly, the difference between high and low doses was of reasonable magnitude with a significant risk ratio of 0.59 despite the low numbers. Thirdly, there are plausible biological mechanisms to explain such a finding (uric acid and superoxide anions).

It is worth commenting further on the limitations of the dataset available to us. Firstly, unfortunately we do not have uric acid data because the current computerised biochemistry records were not in operation in the early 1990s and because not every CHF patient would have a routine urate concentration determination unless they had symptoms to suggest gout. Secondly, the only data to reflect CHF disease severity are the furosemide (frusemide) doses. Although this is a fairly reliable measure of CHF severity, the ideal study would also have New York Heart Association functional classes and measures of left ventricular function to define CHF disease severity. Thirdly, because of limitations in the data available to use, we are unable to repeat this study in a larger cohort of patients, although we aim to do this after several years' more collection of data.

\section{Conclusion}

We have found that long term low dose allopurinol is associated with increased mortality while long term high dose allopurinol was associated with the same mortality as in those who received no allopurinol. One possible interpretation of these results is that low dose allopurinol inadequately reduces the adverse effects associated with a longstanding high urate concentration but that high dose allopurinol does reduce the risks associated with a high urate concentration in CHF. It also raises the hypothesis that patients with $\mathrm{CHF}$ who have gout ought to receive $\geqslant 300 \mathrm{mg}$ allopurinol/day even if a lower dose keeps the gout under clinical control. Further work is required to see whether the hypothesis raised by these results is true.

\section{ACKNOWLEDGEMENT}

We thank the Chief Scientist Office for financial support of this study.

\section{Authors' affiliations}

A D Struthers, P T Donnan, P Lindsay, D McNaughton,

J Broomhall, T M MacDonald, Department of Clinical Pharmacology \& Therapeutics, and the Medicines Monitoring Unit, Ninewells Hospital, Dundee DDI 9SY, UK 


\section{REFERENCES}

1 Waring WS, Webb DJ, Maxwell SRJ. Effect of local hyperuricaemia on endothelial function in the human forearm vascular bed. Br J Clin Pharmacol 2000;49:511P.

2 Britten MB, Elsner M, Walter DH, et al. Elevated uric acid levels in hypercholesterolaemia are associated with coronary endothelial dysfunction [abstract]. Circulation 1999/100(Suppl):I-6.

3 Anker SD, Leyva SD, Poole Wilson PA, et al. Uric acid is an independent predictor of impaired prognosis in patients with chronic heart failure. J Am Coll Cardiol 1998;31:154A.

4 Freedman DS, Williamson DF, Gunter EW, et al. Relation of serum uric acid and 11.5 year mortality of middle-aged women: findings of the Chicago Heart Association detection project in industry. J Clin Epidemiol 1989;42:257-67.

5 Liese AD, Hense HW, Lower $\mathrm{H}$, et al. Association of serum uric acid with all cause and cardiovascular disease mortality and incident $\mathrm{Ml}$ in the MONICA Ausburg cohort. Epidemiology 1999;10:391-7.

6 Culleton BF, LarsonMG, Kannel WB, et al. Serum uric acid and risk for cardiovascular disease and death: the Framlington heart study. Ann Intern Med 1999;131:7-13.

7 Ward HJ. Uric acid as an independent risk factor in the treatment of hypertension. Lancet 1998;352;6760-1.

8 Fang J, Alderman MH. Serum uric acid and cardiovascular mortality. The NHANES I epidemiologic follow up study. JAMA 2000;283:240410.

9 Berry C, Hamilton CA, Brosman J, et al. Investigation into the sources of superoxide in human blood vessels: angiotensin II increases superoxide production in human internal mammary arteries. Circulation 2000;101:2206-12.

10 Freidl HP, Till GO, Ryan US, et al. Mediator-induced activation of xanthine oxidase in endothelial cells. FASEB J 1989;3:2512-8.
11 Bulkey GB. Reactive oxygen metabolites and reperfusion injury: aberrant triggering of reticuloendothelial function. Lancet 1994;344:934-6.

12 Reuben GM, Vanhoutte PM. Superoxide anion and hypoxia inactivate endothelium-derived relaxing factor. Am J Physiol 1986:250:H822-7.

13 Gryglewski RJ, Palmer RM, Moncada S. Superoxide anion is involved in the breakdown of endothelial-derived vascular relaxing factor. Nature 1986;320:454-6.

14 Cardillo C, Kilcoyne CM, Cannon RO, et al. Xanthine oxidase inhibition with oxypurinol improves endothelial vasodilator function in hypercholesterolaemic but not in hypertensive patients. Hypertension 1997;30:57-63.

15 Butler R, Morris AD, Belch JJF, et al. Allopurinol normalises endothelial dysfunction in type 2 diabetes with mild hypertension. Hypertension 2000;35:746-51.

16 Farquharson C, Butler RA, Hill A, et al. Allopurinol improves endothelial dysfunction in chronic heart failure [abstract]. J Am Coll Cardiol 1999:33(Suppl A):216A.

17 Evans JMM, McDevitt DG, MacDonald TM. The Tayside Medicines Monitoring Unit (MEMO): a record linkage study for pharmacovigilance. Pharm Med 1995;9:177-84.

18 Struthers AD Anderson G, Donnan PT, et al. Social deprivation increases cardiac hospitalisations in chronic heart failure independently of disease severity and of diuretic non adherence. Heart 2000;83:12-6.

19 McLoone P. Carstairs codes for Scottish postcode sectors from the 1991 census. Glasgow: Public Health Research Unit, University of Glasgow, 1991

20 Loh E, Sutton MS, Wun CCC, et al. Ventricular dysfunction and the risk of stroke after myocardial infarction. N Engl J Med 1997;336:251-7.

21 Grady D, Hulley SB. Hormones to prevent coronary disease in women: when are observational studies adequate evidence? Ann Intern Med 2000;133:999-1001.

\section{IMAGES IN CARDIOLOGY}

\section{Haemopericardium and Brugada-like ECG pattern in rheumatoid arthritis}

$\mathrm{H}$

emopericardium is rare in rheumatoid arthritis. We report a case of pericardial fluid and tumour compressing the right ventricle with Brugada-like ECG pattern in rheumatoid arthritis.

A 44 year old women who had rheumatoid arthritis for 10 years presented with dyspnoea. She was taking chloroquine $250 \mathrm{mg}$ twice daily. On examination her heart rate was 85 beats/min. Jugular venous pressure was increased and a tender hepatomegaly was found. She was apyrexial with normal total and differential leucocyte count. An ECG showed regular rhythm with a pattern similar to those described in the Brugada syndrome (below left, panel A: right bundle branch block (RBBB) pattern with coved ST segment elevation in leads V1-V3). Echocardiography showed a pericardial effusion and a tumour compressing the right ventricle. A pericardial drain was inserted and $200 \mathrm{ml}$ haemorrhagic fluid was drained, but the large

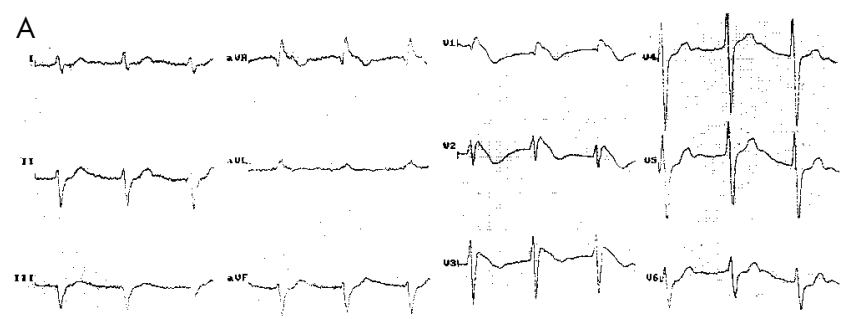

B

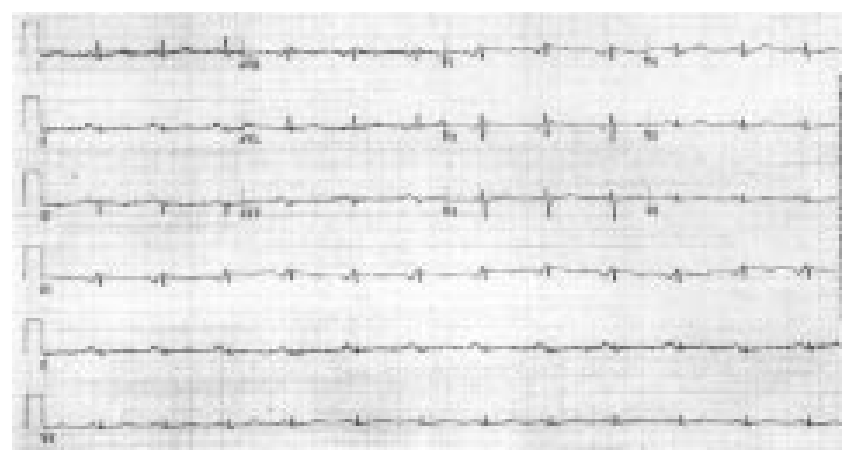

pericardial mass did not disappear (below right). Microscopy and culture, including for acid-fast bacteria and cytology, were negative. During the operation macroscopic evidence revealed that the tumour was organised haemopericardium. After the operation the patient was well and had a normal ECG pattern (below left, panel B).

The diagnostic criteria for Brugada syndrome are rather uncertain. This report described a women in whom the mechanism for the RBBB pattern and ST segment elevation in the right precordial leads was probably the pericardial haematoma compressing the right ventricle.

J Tomcsányi

T Simor

L Papp

tomcsanyi.janos@mail.matav.hu

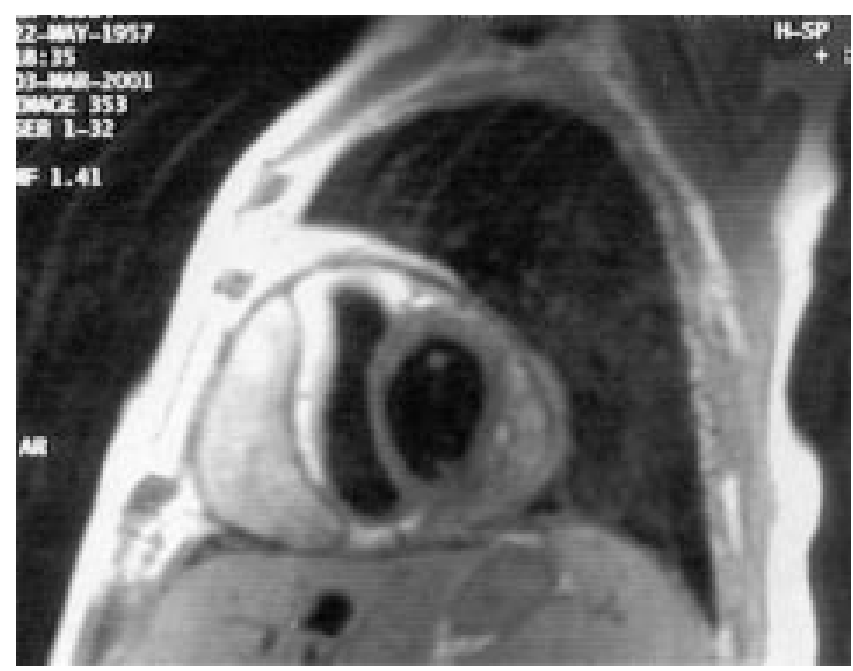

